\title{
REDUÇÃO DA CONTAMINAÇÃO INICIAL DE CARNE BOVINA PELA SANITIZAÇÃO COM ÁCIDOS ORGÂNICOS
}

\author{
JOÃO ANDRADE SILVA* \\ NELSON JOSÉ BERAQUET**
}

\begin{abstract}
Ácidos orgânicos diluídos foram utilizados na sanitização do tensor fasciae lateae bovino para reduzir sua microbiota superficial e aumentar a vida-de-prateleira da carne refrigerada. Após os tratamentos e em intervalos de três e cinco dias de estocagem realizou-se análises microbiológicas, determinação de perda de peso, verificação do $\mathrm{pH}$ e análise sensorial. Os tratamentos reduziram significativamente a carga microbiana dos músculos e mantiveram esta redução pelo período de nove dias. Nos músculos submetidos aos tratamentos observouse perdas de peso superiores ao grupo controle. Após três dias de estocagem, os escores atribuídos aos músculos tratados com a solução de ácidos orgânicos e ao controle foram estatisticamente superiores aos dos músculos tratados com a solução ácida, seguida de alginato de cálcio e aos tratados com a solução ácida mais alginato de cálcio. Verificou-se também que os tratamentos não modificaram a aparência dos músculos.
\end{abstract}

\section{INTRODUÇÃO}

A maior parte da microbiota da carne in natura encontra-se em sua superfície $(15,25)$. Este conhecimento é absolutamente necessário, e considerado fator principal, quando se procura estabelecer técnicas para melhorar a conservação deste produto (26). A vida-de-prateleira da carne fresca é determinada pela sua microbiota inicial e pela temperatura de estocagem das carcaças $(12,16,29)$. A lavagem de carcaças

* Professor Adjunto, Doutor do Departamento de Nutrição, Universidade Federal da Paraíba (UFPB), João Pessoa, PB - Brasil.

** Diretor Geral do Instituto de Tecnologia de Alimentos (ITAL), Campinas, SP - Brasil. 
no final do processo de abate, para remover materiais estranhos, como partículas do solo $(8,35)$ é uma prática normal em abatedouros comerciais, porém, a sanitização ainda não é rotina nestes estabelecimentos. A lavagem remove partículas grosseiras como cabelos, poeira e outros elementos (11), já a sanitização reduz a carga microbiana $(5,20)$. Durante a esfola e a evisceração, a carcaça está exposta à contaminação por pelos, fezes, sujidades veiculadas pelo ar, manipuladores, equipamentos e utensílios (32). Estes elementos, definidos como contaminação visível, podem ser removidos pela lavagem com água potável, o que pode também remover microrganismos, que ainda não se encontrem fortemente aderidos à superfície $(26,36)$. DICKSON \& ANDERSON (10) revisando cuidadosamente a literatura existente sobre os materiais e métodos de limpeza e sanitização de carcaças observaram que, a aplicação de boas práticas de processamento reduz significativamente o número de microrganismos patógenos e deterioradores. O fator mais importante para controlar o grau de contaminação da carne fresca é a higienização $(18,26,30,33)$. No entanto, apesar do aumento e da sofisticação nos cuidados higiênicos e na sanitização da superfície da carcaça, ainda são encontrados contaminantes patogênicos como Campylobacter e Salmonella em sua superfície $(9,24,33$.

Sanitizantes como hipoclorito de sódio e quaternário de amônia são utilizados para destruir microrganismos existentes em superfícies que entram em contato com os alimentos. Alguns agentes de sanitização, como os ácidos orgânicos, podem eliminar microrganismos em superfícies de alimentos sólidos como a carne $(2,3,31)$. Os ácidos acético e lático são recomendados por ADAMS \& HALL (1), como sanitizantes em carcaças de animais abatidos para consumo, pelo fato de sua toxicidade ser alta contra os microrganismos e baixa contra os humanos. Segundo CARLET JR. \& BROWN (6) a ação antimicrobiana destes ácidos resulta de sua ação lipofílica, na qual os íons hidrogênio penetram na membrana celular do microrganismo, acidificando o seu interior e assim inibindo o transporte de nutrientes.

WILLIANS et al. (38) utilizaram alginato de cálcio para reduzir a carga microbiana e as perdas de peso da carne bovina. Um grupo de amostras foi submetido ao tratamento e outro foi analisado como controle. A temperatura de armazenamento não foi mencionada pelos autores da pesquisa. Após sete dias de estocagem não havia diferença significativa $(p>0,05)$ entre a 
contagem total de microrganismos do controle e do tratamento. As perdas de peso das amostras revestidas com a camada de alginato de cálcio foram inferiores às do controle. Resultados semelhantes foram observados por LAZARUS et al. (21) ao revestirem carcaças de carneiros com fina camada de alginato de cálcio, armazenando-as a $0^{\circ} \mathrm{C}$ por sete dias.

OSTHOLD et al. (28) utilizaram uma solução de ácidos orgânicos na sanitização de carcaças bovinas. O tratamento foi realizado logo depois do abate dos animais e demonstrou eficiência na redução de Enterobacteriaceae e bactérias aeróbias totais. Após cinco dias de estocagem a $7 \pm 2^{\circ} \mathrm{C}$ verificou-se diferença de $3,5 \mathrm{log} U F C / \mathrm{cm}^{2}$ na população viável de Enterobacteriaceae e $4,0 \quad \log \mathrm{UFC} / \mathrm{cm}^{2}$ de bactérias aeróbias, entre o tratamento e o controle. Nas primeiras 24 horas depois do tratamento as carcaças apresentaram suave porém aceitável aroma ácido. Depois deste período, o aroma não foi mais detectado, provavelmente devido a volatilização do ácido acético. O aspecto geral das carcaças não foi afetado pelo tratamento.

Este trabalho teve como objetivo verificar a viabilidade da sanitização do tensor fasciae lateae bovino, por aspersão de soluções de ácidos orgânicos em sua superfície. Pesquisou-se também a utilização de película pós-formada, com $0,50 \%$ de alginato de sódio e $0,10 \%$ de carbonato de cálcio, para evitar recontaminações e reduzir as perdas de peso da carne durante a estocagem refrigerada a $7 \pm 2^{\circ} \mathrm{C}$. Estudou-se ainda a vida-deprateleira mediante análises físico-químicas, sensoriais e microbiológicas.

\section{MATERIAL E MÉTODOS}

Um grupo de 112 maminhas, tensor fasciae lateae bovino, dividido em quatro grupos iguais foi submetido aos seguintes tratamentos: 1) aspersão com solução contendo $2,00 \%$ de ácido acético, $1,00 \%$ de ácido lático, $0,25 \%$ de ácido cítrico e $0,10 \%$ de ácido ascórbico; 2) aspersão com solução de 2,00\% de ácido acético, 1,00\% de ácido lático, 0,25\% de ácido cítrico e $0,10 \%$ de ácido ascórbico seguida de outra solução contendo $0,50 \%$ de alginato de sódio e $0,10 \%$ de carbonato de cálcio; 3 ) aspersão com solução $2,00 \%$ de ácido acético, 1,00\% de ácido lático, $0,25 \%$ de ácido cítrico e $0,10 \%$ de ácido ascórbico, $0,50 \%$ de alginato de sódio e $0,10 \%$ de carbonato de cálcio; 4) 
sem tratamento (controle).

Antes dos tratamentos caracterizou-se microbiologicamente o tensor fasciae lateae bovino, pela contagem total de bactérias mesófilas, psicrotróficas, bolores e leveduras, Enterobacteriaceae, pesquisa de coliformes e Salmonella sp. Após os tratamentos, os músculos foram armazenados sob refrigeração e submetidos a análises físico-químicas (perda de peso e $\mathrm{pH}$ ), sensoriais (odor, cor e qualidade global) e microbiológicas (contagem total de bactérias psicrotróficas, bolores e leveduras e Enterobacteriaceae) a cada dois ou três dias de armazenamento, até que a equipe de análise sensorial as considerasse inadequadas para consumo.

\subsection{ANÁLISES MICROBIOLÓGICAS}

A amostragem para as determinações microbiológicas foi realizada pela fricção de uma zaragatoa em área contínua de $25 \mathrm{~cm}^{2}$ demarcada por molde metálico estéril. Colocou-se a zaragatoa num tubo contendo $25 \mathrm{~mL}$ de água peptonada $0,10 \%$ $(p / v)$, DIFCO, e agitou-se por dois minutos em agitador de tubos FANEM Mod. 251. Cada mililitro da solução representou $1,0 \mathrm{~cm}^{2}$ de superfície (22). O Quadro 1 resume a metodologia empregada nas análises microbiológicas deste estudo.

\section{QUADRO 1 - METODOLOGIA EMPREGADA NAS ANÁLISES MICROBIOLÓGICAS}

\begin{tabular}{|l|c|c|c|}
\hline Microrganismo & Meio de Cultura & Incubação & $\begin{array}{c}\text { Referência } \\
\text { Bibliográfica }\end{array}$ \\
\hline $\begin{array}{l}\text { Bactérias } \\
\text { Mesófilas }\end{array}$ & Plate Count Agar & $37^{\circ} \mathrm{C} / 48 \mathrm{~h}$ & $\begin{array}{c}\text { VANDERZANT \& } \\
\text { SPLITTSTOOESSER (37) }\end{array}$ \\
\hline $\begin{array}{l}\text { Bactérias } \\
\text { Coliformes }\end{array}$ & $\begin{array}{c}\text { Caldo LST } \\
\text { Caldo BVB } \\
\text { Caldo EC }\end{array}$ & $\begin{array}{c}35^{\circ} \mathrm{C} / 48 \mathrm{~h} \\
35^{\circ} \mathrm{C} / 48 \mathrm{~h} \\
44,4 \pm 0,2^{\circ} \mathrm{C} / 24 \mathrm{~h}\end{array}$ & $\begin{array}{c}\text { VANDERZANT \& } \\
\text { SPLITTSTOOESSER (37) }\end{array}$ \\
\hline $\begin{array}{l}\text { Bactérias } \\
\text { Psicrotróficas }\end{array}$ & Plate Count Agar & $20^{\circ} \mathrm{C} / 72 \mathrm{~h}$ & OLIVEIRA \& PARMELLE \\
\hline Enterobactérias & Ágar Vermelho & $35^{\circ} \mathrm{C} / 24 \mathrm{~h}$ & ICMSF (17) \\
\hline $\begin{array}{l}\text { Bolores e } \\
\text { Leveduras }\end{array}$ & $\begin{array}{c}\text { Potato Dextrose } \\
\text { Agar }\end{array}$ & $25^{\circ} \mathrm{C} / 72 \mathrm{~h}$ & FDA (13) \\
\hline
\end{tabular}




\subsection{DETERMINAÇÃO DA PERDA DE PESO}

Determinou-se a perda de peso pela diferença encontrada entre o peso das maminhas no início do experimento e em pesagens simultâneas às demais determinações, utilizando-se balança Mettler Mod. P5N eletrônica, semi-analítica, com precisão $0,1 \mathrm{~g}$.

\subsection{DETERMINAÇÃO DO pH}

$\mathrm{O} \mathrm{pH}$ foi determinado na superfície dos músculos, antes dos tratamentos e em intervalos coincidentes com as demais análises, utilizando-se potenciômetro portátil Ingold Mod. WTW $\mathrm{pH}$ 91, com eletrodo de vidro apropriado para determinações de $\mathrm{pH}$ em superfícies.

\subsection{ANÁLISE SENSORIAL}

Foi realizada por um painel composto por 10 provadores treinados, em sistema de avaliação sensorial computadorizado desenvolvido pela COMPUSENSE INC. LTDA., versão 4.2 (7). Utilizou-se a escala não estruturada de 0 a 10 pontos ( $0=$ extremamente aceitável a 10=extremamente inaceitável) para os parâmetros odor, cor (superfície e músculo) e qualidade global (23).

\subsection{ANÁLISE ESTATÍSTICA}

Todos as análises foram realizadas em triplicata e os resultados submetidos a análises de variância, pelo teste Tukey e nível de significância de $95 \%$, através do programa estatístico STATGRAPHICS (34).

\section{RESULTADOS E DISCUSSÃO}

\subsection{AVALIAÇÃO MICROBIOLÓGICA}

Nas contagens de bactérias mesófilas, psicrotróficas, bolores e leveduras e Enterobacteriaceae realizadas antes dos tratamentos, encontrou-se $\log 2,40 ; 2,51 ; 1,66$ e $1,12 \mathrm{UFC} / \mathrm{cm}^{2}$ respectivamente. Pela metodologia utilizada, não foi detectada a presença de bactérias do grupo coliforme nem de Salmonella sp. De acordo com FUNG et al. (14) contagens bacterianas 
inferiores a $2 \log U F C / \mathrm{cm}^{2}$ indicam baixa contaminação, contagens entre 3 e $4 \mathrm{log} \mathrm{UFC} / \mathrm{cm}^{2}$ indicam contaminação intermediária e contagens entre 5 e $6 \mathrm{log} \mathrm{UFC} / \mathrm{cm}^{2}$ alta contaminação. Portanto, estes músculos podem ser classificados como contaminação microbiológica intermediária.

No Quadro 2 são apresentados os resultados da contagem total de bactérias psicrotróficas das amostras tratadas e de controle. Até o quinto dia de armazenamento não se detectou diferença estatisticamente significativa $(p>0,05)$ entre as amostras. Após sete dias, os músculos submetidos ao tratamento pela aspersão com a solução de ácidos orgânicos e os músculos tratados com a solução de ácidos orgânicos seguida da solução de alginato de cálcio, apresentaram contagens inferiores às observadas no controle, inclusive com diferença significativa $(p<0,05)$. Embora não tenham apresentado diferença significativa, as contagens de bactérias psicrotróficas encontradas nos músculos tratados com a solução ácida seguida da solução de alginato de cálcio foram inferiores às dos músculos tratados com a solução de ácidos orgânicos contendo alginato de cálcio, durante todo o período em que foram analisados.

No final do ensaio, após nove dias de armazenamento, as contagens continuaram menores para os músculos submetidos aos tratamentos, no entanto, não se detectou diferença significativa $(p>0,05)$ entre as amostras tratadas e de controle. Este aumento no número de microrganismos viáveis nos músculos submetidos aos tratamentos pode ser atribuído a perda da eficiência dos ácidos utilizados na sanitização. Os resultados em questão estão de acordo com relatos de BAIRDPARKER (4) sobre a ação antimicrobiana dos ácidos orgânicos. A perda da eficiência dos ácidos tanto pode ser atribuída ao alto poder tamponante da proteína muscular, como também à evaporação dos ácidos, permitindo assim o crescimento dos microrganismos. Essa última afirmação foi comprovada pelas medidas de $\mathrm{pH}$, discutidas posteriormente.

LAZARUS et al. (21) e WILLIANS et al. (38) estudando a utilização de fina camada de alginato de cálcio sobre a superfície da carne, como forma de reduzir sua carga microbiana obtiveram resultados semelhantes aos encontrados neste trabalho, isto é, não houve diferença significativa $(p>0,05)$ entre os resultados para amostras tratadas e de controle. 
Mesmo sem altas contaminações, todos os músculos foram considerados impróprios à comercialização para consumo humano, pela equipe da análise sensorial, devido a sua aparência seca e sem brilho, características próprias de carne deteriorada.

A presença de Enterobacteriaceae só foi detectada no controle, com valores de $\log 1,09 ; 0,85 ; 2,19 ; 1,85$ e $3,35 \mathrm{UFC} / \mathrm{cm}^{2}$ aos $0,2,5,7$ e 9 dias, respectivamente, verificando-se evolução de crescimento, com o tempo de armazenamento refrigerado. Estes resultados indicam que todos os tratamentos foram eficientes na supressão do crescimento deste grupo de microrganismos.

Conforme Quadro 3 os resultados das análises realizadas dois dias depois dos tratamentos mostraram sensível redução na contagem total de bolores e leveduras. Após cinco dias de armazenamento, os valores encontrados, nos tratamentos foram superiores aos do controle. Nas análises seguintes, aos sete e nove dias de estocagem o número de bolores e leveduras encontradas nas amostras de controle superou o das amostras tratadas. O aumento da contagem total destes microrganismos, na superfície dos músculos submetidos a tratamentos com soluções de ácidos orgânicos corrobora as observações de OSTHOLD et al. (28), segundo as quais a redução do $\mathrm{pH}$ da superfície da carne estimula o seu crescimento, durante o armazenamento refrigerado.

QUADRO 2 - BACTÉRIAS PSICROTRÓFICAS DO Tensor fasciae lateae BOVINO, APÓS TRATAMENTOS E DURANTE ARMAZENAMENTO A $7 \pm 2^{\circ} \mathrm{C}$ (LOG UFC/ $\mathrm{cm}^{2}$ )

\begin{tabular}{|c|c|c|c|c|}
\hline \multirow[t]{2}{*}{ Tempo (dias) } & \multicolumn{4}{|c|}{ Tratamento } \\
\hline & Controle $^{1}$ & Ácidos ${ }^{1}$ & Ác./Alginato ${ }^{1}$ & Ác.+Alginato ${ }^{1}$ \\
\hline $\mathbf{0}$ & 2,50 & n.r. & n.r. & n.r. \\
\hline 2 & $1,99^{\mathrm{a}}$ & $1,03^{\mathrm{a}}$ & $1,27^{\mathrm{a}}$ & $1,19^{\mathrm{a}}$ \\
\hline 5 & $2,79^{\mathrm{a}}$ & $3,17^{\mathrm{a}}$ & $2,43^{\mathrm{a}}$ & $2,93^{\mathrm{a}}$ \\
\hline 7 & $5,54^{\mathrm{b}}$ & $4,52^{\mathrm{a}}$ & $4,54^{\mathrm{a}}$ & $4,88^{a, b}$ \\
\hline 9 & $5,45^{\mathrm{a}}$ & $4,62^{\mathrm{a}}$ & $4,51^{\mathrm{a}}$ & $4,89^{\mathrm{a}}$ \\
\hline
\end{tabular}




\section{QUADRO 3 - BOLORES E LEVEDURAS DO Tensor fasciae lateae BOVINO, APÓS TRATAMENTOS E DURANTE ARMAZENAMENTO A $7 \pm 2^{\circ} \mathrm{C}$ (LOG $\mathrm{UFC} / \mathrm{cm}^{2}$ )}

\begin{tabular}{|c|c|c|c|c|}
\hline Tempo (dias) & \multicolumn{4}{|c|}{ Tratamento $^{\mid}$} \\
\hline & Controle $^{1}$ & Ácidos $^{1}$ & Ác./Alginato $^{1}$ & Ác. + Alginato $^{1}$ \\
\hline 0 & 2,33 & n.r. & n.r. & n.r. \\
2 & $1,10^{\mathrm{a}}$ & $1,33^{\mathrm{a}}$ & $1,12^{\mathrm{a}}$ & $1,03^{\mathrm{a}}$ \\
5 & $1,78^{\mathrm{a}}$ & $2,07^{\mathrm{a}}$ & $2,34^{\mathrm{a}}$ & $2,43^{\mathrm{a}}$ \\
7 & $4,50^{\mathrm{b}}$ & $3,61^{\mathrm{a}}$ & $4,46^{\mathrm{b}}$ & $3,25^{\mathrm{a}}$ \\
9 & $4,90^{\mathrm{a}}$ & $4,66^{\mathrm{a}}$ & $4,44^{\mathrm{a}}$ & $4,84^{\mathrm{a}}$ \\
\hline
\end{tabular}

Obs.: Diferentes letras, na mesma linha, indicam diferenças significativas $(p<0,05)$ entre as médias

${ }^{1}$ Média de três repetições.

n.r = análise não realizada.

\subsection{PERDA DE PESO}

A perda de peso das amostras tratadas e de controle, durante estocagem a $7 \pm 2^{\circ} \mathrm{C}$ são apresentadas no Quadro 4. Após um dia de armazenamento observou-se que, os músculos submetidos ao tratamento com a solução de ácidos orgânicos mais alginato de cálcio apresentavam as menores perdas de peso. As maiores perdas foram observadas no controle. A partir do quinto dia de armazenamento, as menores perdas foram observadas no controle, seguido pelos músculos tratados com a solução de ácidos orgânicos. No final do experimento, aos nove dias, todas as amostras tratadas apresentaram perdas de peso superiores ao controle. Os músculos tratados com a solução de ácidos orgânicos mais alginato de cálcio apresentaram as maiores perdas. Estes resultados não confirmam os dados apresentados por KESTER \& FENNEMA (19), segundo os quais uma fina camada de alginato de cálcio na superfície de carnes reduziria as perdas de peso, durante o armazenamento sob refrigeração. LAZARUS et al. (21) também reduziram em mais de $10 \%$, as perdas de peso de carcaças de carneiros armazenadas a $2^{\circ} \mathrm{C}$ por sete dias, cobertas por uma fina camada de alginato de cálcio. 


\section{QUADRO 4 - PERCENTAGEM DAS PERDAS DE PESO DO Tensor fasciae lateae BOVINO, DURANTE ARMAZENAMENTO A $7 \pm 2^{\circ} \mathrm{C}$}

\begin{tabular}{|c|c|c|c|c|}
\hline \multirow{2}{*}{ Tempo (dias) } & \multicolumn{4}{|c|}{ Tratamento } \\
\cline { 2 - 5 } & Controle $^{1}$ & Ácidos $^{1}$ & Ác./Alginato & Ác. + Alginato \\
\hline 1 & $0,88^{\mathrm{b}}$ & $0,52^{\mathrm{a}, \mathrm{b}}$ & $0.55^{\mathrm{a}, \mathrm{b}}$ & $0,35^{\mathrm{a}}$ \\
3 & $2,59^{\mathrm{a}}$ & $2,49^{\mathrm{a}}$ & $2,98^{\mathrm{a}}$ & $2,97^{\mathrm{a}}$ \\
5 & $4,05^{\mathrm{a}}$ & $5,06^{\mathrm{a}}$ & $5,53^{\mathrm{a}}$ & $5,35^{\mathrm{a}}$ \\
7 & $5,52^{\mathrm{a}}$ & $6,93^{\mathrm{a}}$ & $7,64^{\mathrm{a}}$ & $7,63^{\mathrm{a}}$ \\
9 & $6,31^{\mathrm{a}}$ & $8,06^{\mathrm{a}, \mathrm{b}}$ & $8,77^{\mathrm{a}, \mathrm{b}}$ & $9,00^{\mathrm{b}}$ \\
\hline
\end{tabular}

Obs.: Diferentes letras, na mesma linha, indicam diferenças significativas $(p<0,05)$ entre as médias

${ }^{1}$ Média de três repetições.

As maiores perdas de peso observadas, nos músculos submetidos aos tratamentos, podem ter sido causadas pelo efeito desnaturante dos ácidos aspergidos na sua superfície. As proteínas exsudadas no corte do músculo formam um filme protéico, diminuindo a taxa de perdas de umidade, durante o armazenamento refrigerado. Nos músculos submetidos aos tratamentos, os ácidos desnaturaram as proteínas da superfície da carne impedindo a formação desta película. O próprio alginato de cálcio pode ter funcionado como veículo de absorção de água do músculo, facilitando a sua remoção pelo ar circulante.

\subsection{AVALIAÇÃO DO pH}

Imediatamente após a aspersão das soluções, o pH superficial dos músculos foi reduzido significativamente, situando-se na faixa de 4,0 a 4,2 (Quadro 5). Contudo, após um dia de armazenamento, já não se observou diferença significativa $(p>0,05)$ nos valores de $\mathrm{pH}$ da superfície dos músculos submetidos aos tratamentos e de controle. A elevação dos valores de $\mathrm{pH}$ da superfície dos músculos, nas primeiras horas depois da aspersão da solução de ácidos orgânicos, pode ser atribuída a pequena quantidade de ácidos aspergida na superfície para uma massa muscular de maior volume. O efeito tamponante da proteína muscular tende a neutralizar os ácidos. Durante armazenamento prolongado, reações autolíticas ocasionam a formação de compostos básicos que aumentam o pH e posteriormente a ação proteolítica das bactérias deterioradoras provocam o mesmo efeito. 


\section{QUADRO 5 - MEDIDAS DE pH DO Tensor fasciae lateae BOVINO, APÓS TRATAMENTOS E DURANTE ARMAZENAMENTO A $7 \pm 2^{\circ} \mathrm{C}$}

\begin{tabular}{|c|c|c|c|c|}
\hline \multirow{2}{*}{ Tempo (dias) } & \multicolumn{4}{|c|}{ Tratamento } \\
\cline { 2 - 5 } & Controle $^{1}$ & Ácidos $^{1}$ & Ác./Alginato $^{1}$ & Ác. $+{ }_{1}$ \\
\hline 0 & $5,57^{\mathrm{a}}$ & $4,21^{\mathrm{b}}$ & $4,11^{\mathrm{b}}$ & $3,97^{\mathrm{b}}$ \\
1 & $5,35^{\mathrm{a}}$ & $5,24^{\mathrm{a}}$ & $5,33^{\mathrm{a}}$ & $5,12^{\mathrm{a}}$ \\
3 & $5,47^{\mathrm{a}}$ & $5,38^{\mathrm{a}}$ & $5,48^{\mathrm{a}}$ & $5,33^{\mathrm{a}}$ \\
5 & $5,40^{\mathrm{a}}$ & $5,38^{\mathrm{a}}$ & $5,52^{\mathrm{a}}$ & $5,36^{\mathrm{a}}$ \\
7 & $5,67^{\mathrm{a}}$ & $5,56^{\mathrm{a}}$ & $5,74^{\mathrm{a}}$ & $5,51^{\mathrm{a}}$ \\
9 & $5,73^{\mathrm{a}}$ & $5,52^{\mathrm{a}}$ & $5,71^{\mathrm{a}}$ & $5,69^{\mathrm{a}}$ \\
\hline
\end{tabular}

Obs.: Diferentes letras, na mesma linha, indicam diferenças significativas $(p<0,05)$ entre as médias

${ }^{1}$ Média de três repetições.

\subsection{AVALIAÇÃO SENSORIAL}

Os resultados apresentados no Quadro 6 mostram a influência dos tratamentos sobre a aparência do tensor fasciae lateae bovino, logo após os tratamentos e em intervalos de dois ou três dias de armazenamento refrigerado, comparando-os ao controle. Os músculos submetidos aos tratamentos apresentaram leve porém aceitável aroma de ácidos. Após dois dias de armazenamento este aroma não foi mais detectado. Logo depois dos tratamentos não se detectou diferença significativa $(p>0,05)$ na coloração dos músculos. Tais resultados são semelhantes aos relatados por OSTHOLD et al. (28).

Nenhuma das soluções afetou a aparência dos músculos, logo depois de sua aplicação. No terceiro dia de armazenamento, os músculos submetidos ao tratamento com a solução de ácidos orgânicos, seguida da solução de alginato de cálcio e os músculos tratados com a solução de ácidos orgânicos mais alginato de cálcio, receberam escores estatisticamente inferiores aos músculos tratados com a solução de ácidos orgânicos e ao controle. A partir do quinto dia de estocagem os provadores atribuíram os maiores escores aos músculos tratados com a solução de ácidos orgânicos. Embora não tenha 
sido encontrada diferença significativa $(p>0,05)$, aos sete dias de armazenamento, todos os músculos ainda foram considerados aceitáveis. Aos nove dias, apenas os músculos submetidos ao tratamento com a solução de ácidos orgânicos seguida da solução de alginato de cálcio continuaram em condições adequadas para consumo humano.

QUADRO 6 - AVALIAÇÃO SENSORIAL DO Tensor fasciae lateae BOVINO, APÓS TRATAMENTOS E DURANTE ARMAZENAMENTO A $7 \pm 2^{\circ} \mathrm{C}$

\begin{tabular}{|c|c|c|c|c|}
\hline \multirow[t]{2}{*}{ Tempo (dias) } & \multicolumn{4}{|c|}{ Tratamento } \\
\hline & Controle & Ácidos & Ác./Alginato & Ác.+Alginato \\
\hline Odor & & & & \\
\hline 0 & $8,64^{\mathrm{a}}$ & $7,28^{a, b}$ & $6,79^{\mathrm{a}, \mathrm{b}}$ & $5,92^{b}$ \\
\hline 3 & $8,45^{\mathrm{a}}$ & $8,41^{\mathrm{a}}$ & $7,82^{a}$ & $7,82^{\mathrm{a}}$ \\
\hline 5 & $8,79^{a}$ & $8,08^{a}$ & $7,79^{\mathrm{a}}$ & $7,77^{\mathrm{a}}$ \\
\hline 7 & $6,92^{\mathrm{a}}$ & $6,54^{\mathrm{a}}$ & $7,05^{\mathrm{a}}$ & $6,69^{\mathrm{a}}$ \\
\hline 9 & $4,46^{\mathrm{a}, \mathrm{b}}$ & $3,49^{b}$ & $5,82^{a}$ & $5,90^{\mathrm{a}}$ \\
\hline Cor & & & & \\
\hline 0 & $8,36^{\mathrm{a}}$ & $7,15^{\mathrm{a}}$ & $6,82^{\mathrm{a}}$ & $6,44^{\mathrm{a}}$ \\
\hline 3 & $8,30^{\mathrm{a}}$ & $8,93^{a}$ & $7,13^{b}$ & $7,10^{\mathrm{b}}$ \\
\hline 5 & $7,36^{\mathrm{b}}$ & $8,26^{\mathrm{a}}$ & $7,72^{\mathrm{a}, \mathrm{b}}$ & $7,36^{\mathrm{b}}$ \\
\hline 7 & $6,38^{\mathrm{a}}$ & $6,92^{\mathrm{a}}$ & $6,69^{\mathrm{a}}$ & $5,95^{\mathrm{a}}$ \\
\hline 9 & $5,10^{\mathrm{a}}$ & $5,92^{\mathrm{a}}$ & $5,54^{\mathrm{a}}$ & $5,51^{\mathrm{a}}$ \\
\hline Aparência & & & & \\
\hline 0 & $8,59^{a}$ & $7,90^{\mathrm{a}}$ & $6,90^{\mathrm{a}}$ & $6,62^{\mathrm{a}}$ \\
\hline 3 & $8,36^{\mathrm{a}}$ & $9,05^{\mathrm{a}}$ & $7,77^{\mathrm{b}}$ & $7,90^{\mathrm{b}}$ \\
\hline 5 & $7,51^{\mathrm{a}}$ & $8,18^{\mathrm{a}}$ & $8,41^{\mathrm{a}}$ & $7,56^{\mathrm{a}}$ \\
\hline 7 & $5,67^{\mathrm{a}}$ & $5,23^{\mathrm{a}}$ & $5,05^{\mathrm{a}}$ & $5,23^{a}$ \\
\hline 9 & $3,41^{b}$ & $4,87^{\mathrm{a}}$ & $5,33^{a}$ & $4,33^{\mathrm{a}, \mathrm{b}}$ \\
\hline
\end{tabular}

Obs.: Diferentes letras, na mesma linha, indicam diferenças significativas $(p<0,05)$ entre as médias 


\title{
4 CONCLUSÃO
}

A aspersão da solução de ácidos orgânicos sobre o tensor fasciae lateae bovino reduziu significativamente a sua contaminação inicial contribuindo para o aumento da vida-deprateleira da carne armazenada sob refrigeração, sem contudo, afetar suas características organolépticas. A utilização do alginato de cálcio não reduziu a perda de peso nem o crescimento de microrganismos sobre a superfície da carne.

\begin{abstract}
Samples of meat were treated by spraying organic acid solutions to reduce its initial bacterial content and increase its shelf life under refrigerated storage. After treatment and on the third fifth day of storage, samples were analyzed for microbiological, weight loss, $\mathrm{pH}$ and sensorial aspect. The performed treatment reduced microbial load and sustained this reduction for nine days. The weigh loss after treatment was higher for the control group. After three days of storage, the control samples and those submitted to organic acid treatment showed better appearance than the samples treated with organic acid solution followed by calcium alginate. The studied treatment did not modify the muscle structure appearance.
\end{abstract}

\section{REFERÊNCIAS BIBLIOGRÁFICAS}

1 ADAMS, M. R., HALL, C. J. Growth inhibition of food-borne pathogens by lactic and acetic acids and their mixtures. Int. J. Food Sci. Technol., v. 23, n. 3, p. 297-301, 1988.

2 ANDERSON, M. E., MARSHALL, R. T., STRINGER, W. C., NAUMANN, $H, D$. Efficacies of three sanitizes under six conditions of application to surfaces of beef. J. Food Sci., v. 42, n. 2, p. 326329, 1977.

3 ANDERSON, M. E., MARSHALL, R. T., DICKSON, J. Efficacies of acetic, lactic and two mixed acids in reducing numbers of bacteria on surfaces of lean meat. J. Food Safety, v. 12, n. 2, p. 139-147, 1992.

4 BAIRD-PARKER, A. C. Organic acids. In: SILLIKER, J. H. Microbiol ecology of foods. New York: Academic Press, 1980. v. 1, p. 126135. 
5 BARKATE, M. L., ACUFF, G. R., LUCIA, L. M., HALE, D. S. Hot water decontamination of beef carcasses for reduction of initial bacterial numbers. Meat Sci., v. 35, n. 3, p. 397-401, 1993.

6 CARLET Jr., D. A., BROWN, M. H. pH and acidity. In: SILLIKER, J. H. Microbiol ecology of foods. New York : Academic Press, 1980. v. 1 , p. 92-110.

7 COMPUTERIZED SENSORY ANALYSIS (CSA). User guide: version 4.2. Ontário : Compusense Inc., 1992. 225 p.

8 CROUSE, J. D., ANDERSOS, M. E., NAUMANN, H. D. Microbial decontamination and weight of carcass beef as affected by automated washing pressure and length of time of spray. J. Food Prot., v. 51, n. 6, p. 471-474, 1988.

9 DICKSON, J. S. Reduction of bacteria attached to meat surfaces by washing with selected compounds. J. Food Prot., v. 51, n. 11, p. 869-873, 1988.

10 DICKSON, J. S., ANDERSON, M. E. Microbiological decontamination of food animal carcasses by washing and sanitizing systems: a review. J. Food Prot., v. 55, v. 2, p. 133-140, 1992.

11 DIXON, Z. R., VANDERZANT, C., ACUFF, G. R., SAVELL, J. W., JONES, D. K. Effect of acid treatment of beef strip lion steaks on microbiological and sensory characteristics. Int. J. Food Microbiol., v. 5, n. 2, p. 181-186, 1987.

12 ELLERBROEK, L, I., WEGENER, J. F., ARNDT, G. Does spray washing of lamb carcasses alter bacterial surface contamination? J. Food Prot., v. 56, n. 5, p. 432-436, 1993.

13 FOOD AND DRUG ADMINISTRATION. Bacteriological analytical manual for foods. 6.ed. Arlington : AOAC, 1984.

14 FUNG, D. Y. C., KASTNER, C. L., HUNT, M. C., DIKEMAN, M. E., KROPF, D. Mesophilic and psychrtrophc bacteria population on hot-boned and conventionally processed beef. J. Food Prot., v. 43, n. 7, p. 547-550, 1980.

15 GILL, C. O. A review: intrinsic bacteria in meat. J. Appl. Bacteriol., v. 47 , n. 2, p. $367-378,1979$ 
GILL, C. O., PHILLIPS, D. M. The efficiency of storage during distant continental transportation of beef sides and quarters. Food Res. Intern., v. 26, n. 4, p. 239-245, 1993.

17 INTERNATIONAL COMMISSION ON MICROBIOLOGICAL SPECIFICATIONS FOR FOODS (ICMSF). Microorganisms in foods. I. Their significance and methods of enumeration. 2. ed. Toronto : University of Toronto Press. v.1, $434 \mathrm{p}$.

18 KASPROWIAK, R., HECHELMANN, H. Puntos críticos de higiene en los estabelecimentos de sacrifício, de deshuesado y de processamiento de la carne. Fleishwirtsch. (español), v. 1,n. 42, p. 45-51, 1993.

19 KESTER, J. J., FENNEMA, O, R. Edible films and coatings: a review. Food Technol., v. 40, n. 12, p. 47-59, 1986.

20 KOtUlA, A. W., LUSBY, W. R., CROUSE, D. J., VRIES B. Beef carcass washing to reducing bacterial contamination. J. Anim. Sci., v. 39, n. 4, p. 674-679, 1974.

21 LAZARUS, C. R., WEST, R. L., OBLINGER, J. L., PALMER, A. Z. Evaluation of a calcium alginate coating and a protective plastic wrapping for the control of lamb carcass shrinkage. J. Food Sci., v. 41, n. 3, p. 639-641, 1976.

22 LEE, J. Y., FUNG, D. Y. C. Methods for sampling meat surfaces. J. Environm. Health, v. 48, n. 4, p. 200-205, 1986.

23 MORAIS, M. A. C. Métodos para avaliação sensorial de alimentos. 7. ed. Campinas : [s.n.], 1990. 93 p.

24 MOSSEL, D. A. A. Intervention as the rational approach to control diseases of microbial etiology transmitted by foods. J. Food Safety, v. 6, v. 2, p. 89-104, 1984.

25 NORTJE, G. L., NAUDE, R. T. Microbiology of the beef carcass surface. J. Food Prot., v. 44, n. 5, p. 355-358, 1981.

26 NOTTINGHAM, P. M. Microbiology of carcass meats. In: BROWN, M H. Meat microbiology. London: Applied Science, 1982. p. 1365.

27 OLIVEIRA, J. S., PARMELEE, C. E. Rapid enumeration of psychrotrophyc bacteria in raw and pasteurized milk. J. Milk 
Food Technol., v. 39, n. 4, p. 269-272, 1976.

OSTHOLD, W., SHIN, H. K., DRESEL, J., LEISTNER, L. Improving the storage life of carcasses by treating their surfaces with an acid spray. Fleishwirtsch., v. 64, n. 7, p. 828-830, 1984.

29 ROBERTS, T. A., HUNDSON, W. R., WHELEHAN, O. P. Number and distribution of bacteria on some beef carcasses at selected abattoirs in some number states of the Europen Communites.

Meat Sci., v. 11, n. 3, p. 191-205, 1984.

30 SCHMIDT, U. Cleaning and desinfection methods, effects of rinsing on surface bacterial count. Fleischwirtsch., v. 67, n. 1, p. 71-74, 1989.

31 SIRAGUSA, G. R., DICKSON, J. S. Inhibition of Listeria monocytogenes, Salmonella tiphimurium and Escherichia coli 0157:H7 on beef muscle tissue by lactic or acetic acid contained in calcium alginate gels. J. Food Safety, v. 13, n. 2, p. 147-158, 1993.

32 SMULDERS, F. J. M., WOOLTHUIS, C. H. J. Immediate and delayed microbiological effects of lactic acid decontamination of calf carcasses cuts. J. Food Prot., v. 48, n. 10, p. 838-847, 1985.

33 SMULDERS, F. J. M., BARENDSEN, P., van LOGTESTIJN, J. G., MOSSEL, D. A. A., van der MARREL, G. M. Review: lactic acid: considerations in favour of its acceptance as a meat decontaminant. J. Food Tecnol., v. 21, n. 4, p. 419-436, 1986.

34 STATGRAPHICS. Statistical graphics system: v. 4.0. Ontário : Statistical Graphics Corporation, 1989.

35 TORPOFF, J., SWIENTEK, R. J. Beef carcass washing system cuts cleaning time $85 \%$. Saves energy-by using plant's existing cold water supply, cuts water usage $25 \%$. Food Proc., v. 42, n. 9, p. 82, 1981.

36 VANDERZANT, C., CARPENTER, Z. L., SMITH, G. C. Sampling carcasses and meat products. In: ANNUAL RECIPROCAL MEAT CONFERENCE, 29., Provo, jun. 20-23, 1976. Proceedings... Provo : National Live Stock and meat Board, 1976. p. 258-267.

37 VANDERZANT, C., SPLITTSTOOSSER, R. D. F. Compendium of methods for the microbiological examination of foods. 15.ed. Washington, DC. : APHA, 1992. $1219 \mathrm{p}$. 
38 WILLIANS, S. K., OBLINGER, J. L., WEST, R. L. Evaluation of a calcium alginate film for use on beef cuts. J. Food Sci., v. 43, n. 2, p. 292-296, 1978. 